\title{
MUSCLE WASTING AFTER 48 HOURS OF FOOD DEPRIVATION DIFFERS BETWEEN MOUSE STRAINS AND IS PROMOTED BY MYOSTATIN DYSFUNCTION
}

\author{
Petras Minderis ${ }^{1}$, Indrẻ Libnickienè ${ }^{1}$, Aivaras Ratkevičius ${ }^{1,2}$ \\ Lithuanian Sports University', Kaunas, Lithuania \\ University of Aberdeen', Aberdeen, Scotland, UK
}

\begin{abstract}
Background. Genetic factors play an important role in determining muscle mass. Indeed, myostatin dysfunction is associated with a pronounced muscle hypertrophy. The aim of our study was to test the hypothesis that starvation induced muscle wasting differs between $\mathrm{BEH}+/+$ and $\mathrm{C} 57 \mathrm{BL} / 6 \mathrm{~J}$ strains of mice and myostatin dysfunction prevents muscle wasting in BEH strain.

Methods. 18-week-old males of C57BL/6J, BEH+/+ and BEH were subjected to $48 \mathrm{~h}$ food deprivation (FD). $\mathrm{C} 57 \mathrm{BL} / 6 \mathrm{~J}$ mice were representatives of classic mouse strain. $\mathrm{BEH}$ mice which differ from $\mathrm{BEH}+/+$ mice by Compact mutation in the Mstn gene represented a model for myostatin dysfunction. All mice were divided into experimental and control groups. The control groups consisted of mice fed ad libitum. Seven mice were studied in each group. Mice were weighed before as well as $24 \mathrm{~h}$ and $48 \mathrm{~h}$ after FD which was followed by dissection and weighing of the hindlimb skeletal muscle.

Results. BEH and $\mathrm{BEH}+/+$ mice showed a similar $(16.9 \pm 1.4 \%$ vs. $19.3 \pm 2.4 \%, p>.05)$ loss of body mass while loss of body mass in C57BL/6J mice was the greatest $(24.8 \pm 1.9 \%, p<.001)$ after FD. The loss of muscle mass was significant in both $\mathrm{BEH}(p<.001)$ and $\mathrm{C} 57 \mathrm{BL} / 6 \mathrm{~J}(p<.01)$ mice, but it was below the level of significance $(p>.05)$ in $\mathrm{BEH}+/+$ mice.

Conclusions. Myostatin dysfunction promotes muscle atrophy after FD. During short periods of FD, BEH+/+ mice are more resistant to body and muscle loss compared to C57BL/6J mice.
\end{abstract}

Keywords: myostatin deficiency, food withdrawal, starvation, muscle atrophy.

\section{INTRODUCTION}

$\mathrm{S}$ keletal muscle mass comprises $40-50 \%$ of body mass and is associated with health and well-being of humans (Wolfe, 2006). On the other hand, muscle wasting is often a consequence of many chronic diseases which have a deteriorating effect on the quality of life (Schiaffino, Dyar, Ciciliot, Blaauw, \& Sandri, 2013). Dietary manipulations which are often associated with a caloric restriction can also cause a decrease in both body and muscle mass (Matsakas et al., 2013). Extent of muscle wasting depends on the magnitude of caloric restriction and food deprivation (FD) or fasting causes the most significant muscle wasting (CollinsHooper et al., 2015). There is a significant amount of evidence suggesting that caloric restriction has a beneficial effect on health as judged by changes in body composition and lipoprotein profile (Anderson \& Weindruch, 2012). However, the major concern is muscle wasting during those dietary manipulations. It would be beneficial to design strategies to prevent or reduce loss of muscle mass during fasting or caloric restriction. This is especially important in view of the fact that malnutrition and starvation are common amongst the ill, venerable and ageing (Elia \& Stratton, 2000). Indeed, age related loss of muscle mass might exaggerate the negative effects of caloric restriction on skeletal muscles (Yanai, 2015). 
Myostatin, which belongs to TGF- $\beta$ superfamily of secreted growth factors, is a negative regulator of skeletal muscle mass (McPherron, Lawler, \& Lee, 1997). Mammalian species with a constitutive myostatin knockout (KO) show pronounced muscle hypertrophy (McPherron et al., 1997, Schuelke et al., 2004). Inhibition of myostatin in adult mice can also increase muscle mass (Whittemore et al., 2003; Personius et al. 2010), since myostatin inhibition increases protein synthesis and decreases protein breakdown in skeletal muscles (Lipina, Kendall, McPherron, C., Taylor, \& Hundal, 2010; Schiaffino et al., 2013). Myostatin expression is upregulated in many pathological conditions leading to muscle wasting (Costelli et al., 2008; Gonzalez-Cadavid et al., 1998; Gruson, Ahn, Ketelslegers, \& Rousseau, 2011; Plant et al., 2010). Thus myostatin inhibition might be a useful intervention protecting skeletal muscle from atrophy under various pathological conditions and ageing. In fact, myostatin inhibition leads to partial improvements in muscle mass and function of $m d x$ mice, a model for Duchenne muscle dystrophy (Bogdanovich et al., 2002). Evidence about effects of myostatin inhibition on skeletal muscles during various catabolic states is sparse and ambiguous. It appears that myostatin KO prevents from glucocorticoid-induced muscle atrophy (Gilson et al., 2007) but not from muscle wasting after hindlimb suspension (McMahon et al., 2003).

It is unclear if myostatin inhibition could prevent from muscle wasting during FD. The results of a few studies in this area are contradictory (Allen, Cleary, Lindsay, Loh, \& Reed, 2010; CollinsHooper et al., 2015). Both of these studies used C57BL6/J mice. However, effects of myostatin inhibition are likely to be strain dependent as mouse strains vary significantly in body mass, muscle mass as well as muscle fibre composition (Lionikas et al., 2013a). Berlin high (BEH) strain was generated after breeding mice for protein accretion over more than 30 generation (Bünger et al., 2004). It is likely that this strain carries several gene variants which favour accretion of muscle mass. Physiological mechanisms, which are triggered by these gene variants, might interact with myostatin in a different way than in C57BL/6J strain. Thus, it is important to study effects of myostatin inhibition using various mouse strains.

Our primary aim was to test a hypothesis that myostatin dysfunction prevents loss of muscle mass during FD. We compared muscle wasting in BEH strain with dysfunctional myostatin and $\mathrm{BEH}+/+$ strain which carries the functional myostatin. The secondary aim of our study was to examine effects of genetic background on muscle wasting during
FD. Thus we compared $\mathrm{C} 57 \mathrm{BL} / 6 \mathrm{~J}$ and $\mathrm{BEH}+/+$ mice with preserved myostatin function as is the case for many other strains of mice.

\section{METHODS}

Experimental animals. All experimental procedures involving mice were approved by the Lithuanian Republic Alimentary and Veterinary Public Office (no. 0223 in 2012 and no. 10 in 2014). 18 week-old males of BEH+/+, BEH and C57BL/6J were used. BEH mice carry MstnCmpt-dl1Abc (Compact; Cmpt) mutation in both Mstn alleles (Varga et al., 1997). This mutation causes 12-bp deletion in the Mstn gene sequence. As a result, the BEH mice are lacking the functional myostatin (Amthor et al., 2007; Lionikas et al., 2013a, b). $\mathrm{BEH}+/+$ mice with normal myostatin function were generated by crossing BEH mice with the Berlin Low (BEL) strain and then repeatedly backcrossing the offspring to BEH using marker assisted selection for the functional myostatin allele (+) (Amthor et al., 2007; Lionikas et al., 2013b). The breeding pairs of C57BL/6J mice were obtained from the Jackson laboratory (USA) whereas the breeding pairs of the $\mathrm{BEH}$ and $\mathrm{BEH}+/+$ were a generous gift of prof. Lutz Bünger.

Before experiments mice were bred and housed in the animal facilities of Lithuanian Sports University. They were kept in standard cages, one to five individuals per cage at a temperature of 20 $21^{\circ} \mathrm{C}$ and $40-60 \%$ humidity with the normal $12 / 12-\mathrm{h}$ light/dark cycle reversed. Animals were fed standard chow diet $58 \% \mathrm{kcal}$ from carbohydrate, $28.5 \% \mathrm{kcal}$ from protein, $13.5 \% \mathrm{kcal}$ from fat; LabDiet 5001, Saint Louis, USA) and received tap water ad libitum.

Experimental protocol. Two mice of the same strain and similar body weight were assigned either to the control or FD intervention, respectively. The control mouse was provided with ad libitum access to food and water. The FD mouse had ad libitum access to water, but did not receive any food for $48 \mathrm{~h}$. Mice were weighed at $0 \mathrm{~h}, 24 \mathrm{~h}$ and $48 \mathrm{~h}$ of the intervention (Kern 440-45N, Germany). Seven pairs of mice from each of three strains $(\mathrm{BEH}+/+$, $\mathrm{BEH}$ and $\mathrm{C} 57 \mathrm{BL} / 6 \mathrm{~J}$ ) were studied.

At the end of the experiment the mice were euthanized by the exposure to $\mathrm{CO}_{2}$. Immediately afterwards, the heart and the skeletal muscles including gastrocnemius, plantaris, soleus, tibialis anterior and extensor digitorum longus were dissected and weighed (Kern, ABS 80-4, Germany). Before weighing the muscles were freed from all visible tendons and blotted dry rapidly on filter paper. 
Muscle weights were assessed with a precision of 0.1 mg. The skeletal muscle mass was calculated as a sum of masses of all five dissected muscles.

Statistical analysis. All analyses were performed using Prism 6.0 and SPSS 20 software for Windows. All data were tested for normality using the Shapiro-Wilk test. Control and fasted mice were compared with unpaired Student's t-test. One-way ANOVA with Bonferroni's post hoc test was used for comparing strains. For all statistical tests, the level of significance was set a priori at $p<.05$. All data are presented as means $\pm S D$.

\section{RESULTS}

Data on body mass of mice are presented in Figure 1. Before experiments, BEH mice were heavier by $16 \%(p<.001)$ than $\mathrm{BEH}+/+$ mice while C57BL/6J mice were approximately two fold ( $p<$ .001) lighter than both $\mathrm{BEH}+/+$ and $\mathrm{BEH}$ mice. FD induced a decrease $(p<.001)$ in body mass of all three strains. The loss of body mass was greater during the initial $24 \mathrm{~h}$ period of FD compared to the subsequent $24-48 \mathrm{~h}$ period $(p<.001)$.

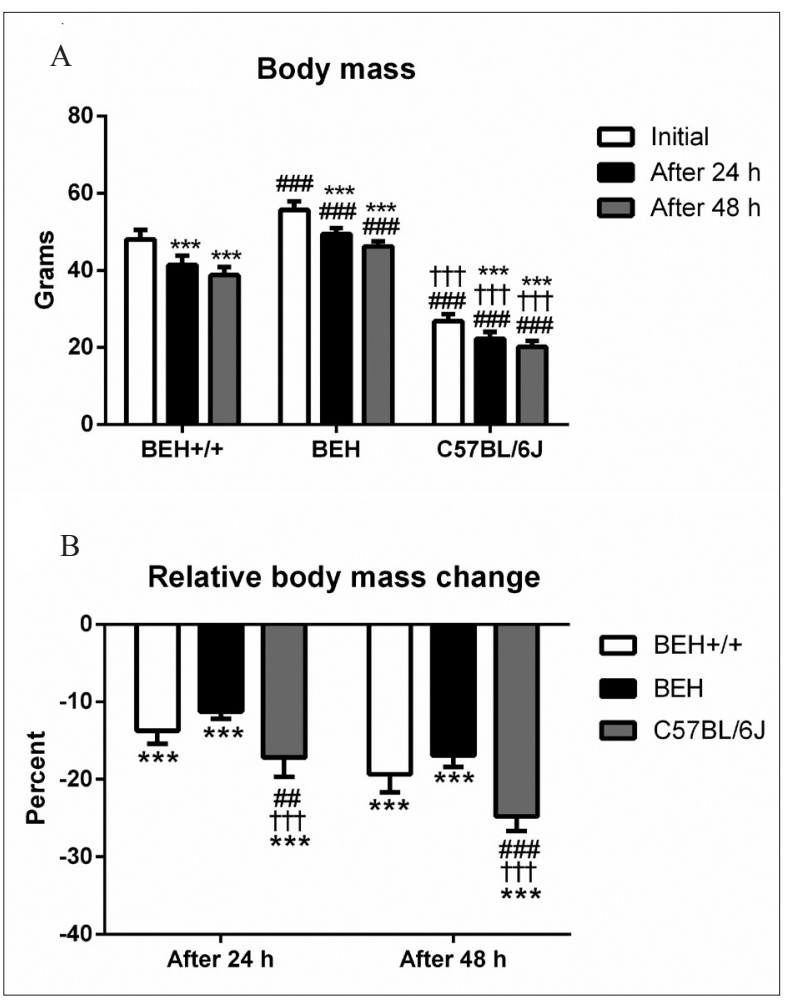

Figure 1. (A) Body mass as well as (B) percentage change in body mass of BEH+/+, BEH and C57BL/6J mice after 24 and $48 \mathrm{~h}$ of food deprivation (FD)

Notes. The relative change in body mass for FD mouse was calculated using the data of the control mouse that initially was matched by weight and belonged to the control group. Values are means $\pm S D$; $* * * p<.001$ vs. initial or previous time point, respectively; ${ }^{\#} p<.01$,

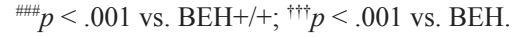

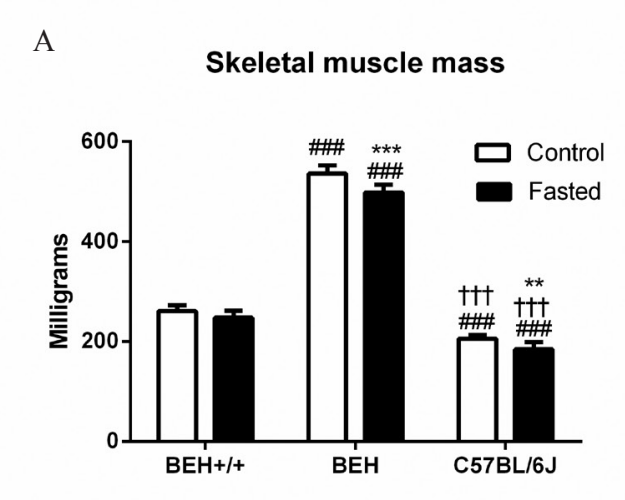

B

\section{Relative skeletal muscle change}

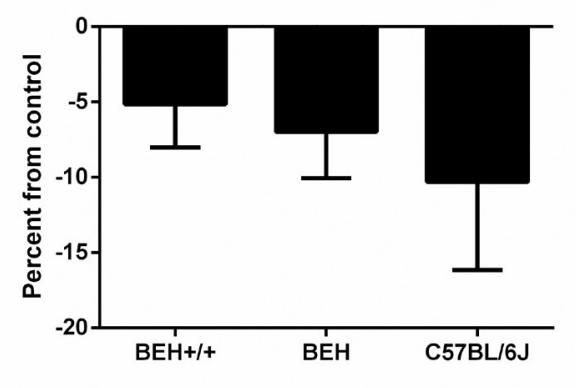

C

Skeletal muscle-to-body mass ratio

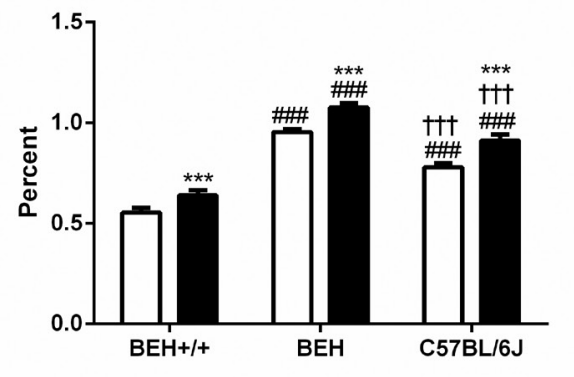

Figure 2. (A) Muscle mass, (B) percentage change in the muscle mass and $(C)$ muscle to body mass ratio in control and fasted BEH+/+, BEH and C57BL/6J mice

Notes. The muscle mass was calculated as the summed weight of gastrocnemius, plantaris, soleus, tibialis anterior and extensor digitorum longus muscles. The relative change in muscle mass for fasted mouse was calculated using the data of the control mouse as in Figure 1. Values are means $\pm S D ; * * p<.01,{ }^{* * *} p<.001$ vs. control; \#\# $p<.001$ vs. $\mathrm{BEH}+/+$; ${ }^{\dagger \dagger} p<.001$ vs. BEH.

C57BL/6J mice showed greater relative decrease in body mass than both $\mathrm{BEH}+/+(p<.01)$ and $\mathrm{BEH}$ mice $(p<.001)$. There were no differences between $\mathrm{BEH}+/+$ and $\mathrm{BEH}$ mice which showed smaller $(p<$ .001) changes in body mass than $\mathrm{C} 57 \mathrm{BL} / 6 \mathrm{~J}$ mice over the entire $48 \mathrm{~h}$ period of FD.

Data on skeletal muscle mass are presented in Figure 2. The skeletal muscle mass depended on mouse strain $(p<.001)$. Muscle mass of BEH mice was $\sim 105$ and $\sim 160 \%$ greater than in $\mathrm{BEH}+/+$ and C57BL/6J mice, respectively. We also evaluated 
the contribution of skeletal muscle to overall body mass by calculating a ratio of muscle to body mass. Skeletal muscle to body mass ratio of BEH mice was by $\sim 72 \%$ and $\sim 23 \%$ greater compared to $\mathrm{BEH}+/+$ and $\mathrm{C} 57 \mathrm{BL} / 6 \mathrm{~J}$ mice, respectively. This ratio for $\mathrm{C} 57 \mathrm{BL} / 6 \mathrm{~J}$ strain was by $\sim 41 \%$ greater than for $\mathrm{BEH}+/+$ mice. $\mathrm{FD}$ caused a decrease in muscle mass of BEH $(p<.001)$ and $\mathrm{C} 57 \mathrm{BL} / 6 \mathrm{~J}$ $(p<.01)$ mice, but had little effect on muscle mass of $\mathrm{BEH}+/+$ mice (Figure 2A). A relative decrease in muscle mass tended to be greater for both $\mathrm{BEH}$ and $\mathrm{C} 57 \mathrm{BL} / 6 \mathrm{~J}$ mice compared to $\mathrm{BEH}+/+$ mice though the differences were not significant (Figure 2B). Muscle to body mass ratio increased $(p<.001)$ after FD in all three strains.

Data on changes in specific skeletal muscles are presented in Table. BEH mice had greater mass of all skeletal muscles than $\mathrm{BEH}+/+$ mice with differences ranging from 1.7 to 2.6 times for soleus and plantaris, respectively. C57BL/6J mice had the smallest muscles which were two-three fold lighter than in BEH mice and 5-27\% lighter than in $\mathrm{BEH}+/+$ mice. There was a significant variation in extent of atrophy between the skeletal muscles after FD. $48 \mathrm{~h}$ FD induced a significant wasting of the gastrocnemius mass in $\mathrm{BEH}+/+(p<.05), \mathrm{BEH}$ $(p<.001)$ and $\mathrm{C} 57 \mathrm{BL} / 6 \mathrm{~J}(p<.01)$ mice. Plantaris lost weight in C57BL/6J $(p<.01)$ and BEH mice $(p<.01)$, but remain unchanged in $\mathrm{BEH}+/+$ mice. Soleus became lighter in C57BL/6J $(p<.05)$ and $\mathrm{BEH}$ mice $(p<.05)$, but did not change in $\mathrm{BEH}+/+$ mice. The weight of the tibialis anterior muscle mass decreased only in C57BL/6J mice $(p<.05)$. Extensor digitorum longus showed loss of mass in all three strains, i.e. BEH $+/+(p<.01), \mathrm{BEH}$ $(p<.01)$ and C57BL/6J $(p<.05)$. In summary, $\mathrm{BEH}+/+$ mice experienced loss of mass in two muscles (gastrocnemius and extensor digitorum longus), $\mathrm{BEH}$ in four muscles (gastrocnemius, plantaris, soleus and extensor digitorum longus) and $\mathrm{C} 57 \mathrm{BL} / 6 \mathrm{~J}$ in all five muscles (gastrocnemius, plantaris, soleus, tibialis anterior and extensor digitorum longus).

Heart mass is presented in Figure 3. BEH mice had similar heart mass to $\mathrm{BEH}+/+$ mice. $\mathrm{C} 57 \mathrm{BL} / 6 \mathrm{~J}$ mice had the lightest hearts $(p<.001)$. Heart to body

Table. Muscle mass for BEH+/+, BEH and C57BL/6J mice from the control (CON) and food deprivation (FD) groups

\begin{tabular}{|c|c|c|c|c|c|c|}
\hline Strain & Group & GAS (mg) & PL (mg) & SOL (mg) & TA (mg) & EDL (mg) \\
\hline \multirow{2}{*}{$\mathrm{BEH}+/+$} & $\mathrm{CON}$ & $154.1 \pm 9.8$ & $17.2 \pm 1.2$ & $10.0 \pm 0.6$ & $66.6 \pm 2.4$ & $12.9 \pm 0.6$ \\
\hline & FD & $142.6 \pm 7.7^{*}$ & $16.6 \pm 1.6$ & $9.9 \pm 0.7$ & $66.9 \pm 5.7$ & $11.6 \pm 0.8^{* *}$ \\
\hline \multirow{2}{*}{$\mathrm{BEH}$} & $\mathrm{CON}$ & $323.6 \pm 12.1^{\# \# \#}$ & $44.0 \pm 1.9^{\# \# \#}$ & $17.3 \pm 1.0^{\# \# \#}$ & $123.4 \pm 6.1^{\# \# \# ~}$ & $27.3 \pm 1.2^{\# \# \#}$ \\
\hline & FD & $299.8 \pm 8.7$ \#\#**** & 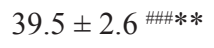 & $16.2 \pm 0.5^{\# \# * *}$ & $117.6 \pm 7.1^{\# \# \#}$ & $24.9 \pm 1.2^{\# \# * * *}$ \\
\hline \multirow{2}{*}{$\mathrm{C} 57 \mathrm{BL} / 6 \mathrm{~J}$} & $\mathrm{CON}$ & $121.8 \pm 5.3^{\# \#+1 \dagger \dagger}$ & $16.3 \pm 0.4^{\dagger \dagger \dagger}$ & $8.2 \pm 0.5^{\# \#+1 \dagger \dagger}$ & $48.9 \pm 2.2^{\# \#+1 \dagger}$ & $10.0 \pm 0.6^{\mathrm{\# \# \# + \dagger \dagger}}$ \\
\hline & FD & $109.2 \pm 9.1^{\mathrm{H} \#+1+\dagger * *}$ & $14.6 \pm 1.2^{+\dagger+* *}$ & $7.4 \pm 0.7^{\# \#+1 \dagger *}$ & $43.8 \pm 4.0^{\# \#+1+\uparrow *}$ & $9.1 \pm 0.6^{\# \#+1+* *}$ \\
\hline
\end{tabular}

Note. Values are means $\pm S D$; GAS, gastrocnemius; PL, plantaris; SOL, soleus; TA, tibialis anterior; EDL, extensor digitorum longus. ${ }^{*} p<.05$, ${ }^{* *} p<.01$ and ${ }^{* * *} p<.001$ vs. control, ${ }^{\# \# \#} p<.001$ vs. $\mathrm{BEH}+/+,{ }^{\dagger t} p<.001$ vs. $\mathrm{BEH}+$.

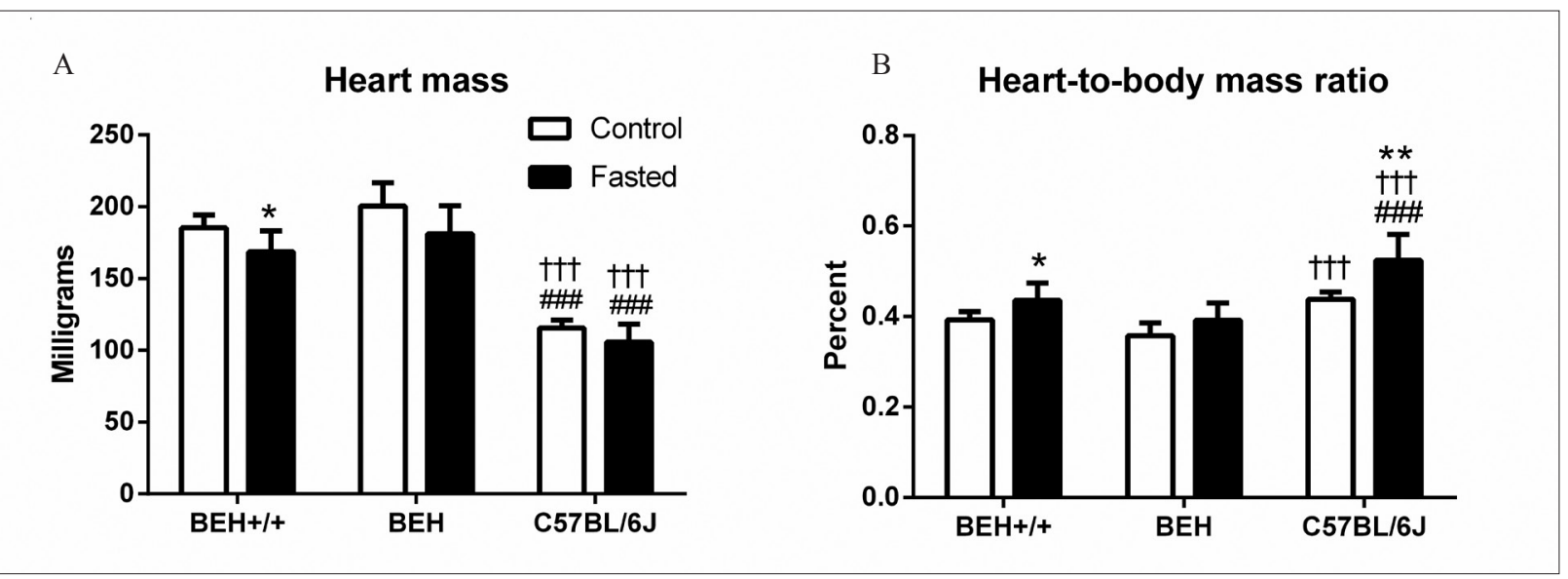

Figure 3. (A) Heart mass and (B) heart mass to body mass ratio in control and fasted mice of BEH+/+, BEH and C57BL/6J strains Note. Values are means $\pm S D ; * p<.05, * * p<0.01$ vs. control; ${ }^{* \# \#} p<.001$ vs. BEH $+/+;{ }^{\dagger \dagger} p<.001$ vs. BEH. 
mass ratio was the greatest $(p<.001)$ in $\mathrm{C} 57 \mathrm{BL} / 6 \mathrm{~J}$ mice and this was especially clear after $48 \mathrm{~h}$ FD. A trend towards reduced heart mass was observed in all mice after $\mathrm{FD}$, but it was significant $(p<.05)$ only for $\mathrm{BEH}+/+$ mice. Heart to body mass ratio increased in $\mathrm{BEH}+/+(p<.05)$ and $\mathrm{C} 57 \mathrm{BL} / 6 \mathrm{~J}$ mice $(p<.01)$ after FD.

\section{DISCUSSION}

The main aim of this study was to examine effect of myostatin dysfunction and genetic background on body and skeletal muscle atrophy after $48 \mathrm{~h}$ food deprivation (FD). Firstly, we hypothesized that myostatin dysfunction might prevent muscle atrophy. However, our results do not confirm this hypothesis. On the opposite, muscle mass of BEH mice showed greater atrophy compared to $\mathrm{BEH}+/+$ mice. Secondly, we have hypothesized that FD induced muscle atrophy will differ between the strains of mice due to genetic factors. Indeed, C57BL/6J mice showed greater loss of body and muscle mass than $\mathrm{BEH}+/+$ mice. This might be due to higher content of body fat in $\mathrm{BEH}+/+$ mice than $\mathrm{C} 57 \mathrm{BL} / 6 \mathrm{~J}$ though potential differences in metabolic rate between the mice could also play the role.

Myostatin dysfunction or myostatin $\mathrm{KO}$ is associated with profound muscle hypertrophy in various mammalian species (McPherron et al., 1997; Schuelke et al., 2004). Indeed, BEH mice with myostatin dysfunction showed two fold greater muscle mass compared to the $\mathrm{BEH}+/+$ mice of the same genetic background, but with the preserved myostatin function. Increased skeletal muscle mass is a consequence of both hypertrophy and hyperplasia of muscle fibres (McPherron et al., 1997). The regulation of fibre number by myostatin most likely results from direct effects of myostatin on proliferation and/or differentiation of myoblasts during the development (Lee, 2004), whereas the regulation of fibre size is a result of increased protein synthesis (Lipina et al., 2010; Welle, Bhatt, \& Pinkert, 2006) and/or activation of satellite cells (McCroskery, Thomas, Maxwell, Sharma, \& Kambadur, 2003). Interestingly, myostatin deficiency seems to have little effect or even causes a slight reduction in the size of other organs (Bünger et al., 2004; Lin et al., 2002). It is probably associated with limited expression and activity of myostatin in tissues other than skeletal muscle (McPherron et al., 1997; Ji et al., 1998). Furthermore, studies with myostatin KO species clearly demonstrate that myostatin dysfunction leads not only to increased skeletal muscle mass but also to decreased fat content (Lin et al., 2002; McPherron et al., 1997; McPherron \& Lee, 2002). Mean total body fat mass was reduced by $70 \%$ in myostatin KO mice compared to wild type (WT) mice (McPherron \& Lee, 2002). In confirmation of these findings by other investigated, BEH mice differed little from $\mathrm{BEH}+/+$ in body mass though had marked greater muscle mass in our study as well. In general, the physiological role of myostatin remains to be investigated in greater detail. There is a clear evidence for skeletal muscle accretion in myostatin deficiency and an increase of myostatin expression during various catabolic diseases (Costelli et al., 2008; Gonzalez-Cadavid et al., 1998; Gruson et al., 2011; Plant et al., 2010). These findings suggest that inactivation of myostatin might be a useful strategy in preserving muscle mass during various conditions and physiological challenges. Indeed, myostatin targeting by antibodies ameliorated muscle wasting in $m d x$ mice which serve as a model for Duchenne muscle dystrophy (Bogdanovich et al., 2002; Wagner, McPherron, Winik, \& Lee, 2002). However, effects of myostatin targeting are less clear under conditions of caloric restriction or fasting which also lead to loss of muscle mass.

Myostatin expression is increased in skeletal muscles of mice after $48 \mathrm{~h} \mathrm{FD}$, but myostatin is not essential for muscle atrophy since myostatin $\mathrm{KO}$ mice undergo a substantial muscle atrophy as well (Allen et al., 2010). Interestingly, Allen et al. (2010) found no differences in muscles atrophy between myostatin $\mathrm{KO}$ and WT mice after $24 \mathrm{~h} \mathrm{FD}$, but after $48 \mathrm{~h}$ FD fast twitch muscles of myostatin KO mice lost less weight compared to muscles of WT mice. Our results seem to contradict these findings. BEH mice with dysfunctional myostatin showed greater muscle atrophy compared to $\mathrm{BEH}+/+$ mice irrespective of the muscles examined. It might be argued that these discrepancies between studies could be due to differences in mouse strains used in these studies. Indeed, we used BEH mice while Allen et al. (2010) studied C57BL/6J mice. However, recent results of Collins-Hooper et al. (2015) on C57BL/6 also contradict those results of Allen et al. (2010). Collins-Hooper et al. (2015) showed that during $24 \mathrm{~h}$ of FD C57BL/6 mice with myostatin $\mathrm{KO}$ mice lost more muscle mass than WT mice and this difference did not depend on the type of muscles studied. Interestingly, caloric restriction of $40 \%$ applied over 5 weeks also resulted in greater muscle atrophy in myostatin 
KO compared to WT mice (Matsakas et al., 2013). Thus, a significant amount of evidence suggests that mice with myostatin deficiency show greater muscle wasting compared to the WT mice during food restriction.

Lean body mass or fat-free mass is the major factor determining basal metabolic rate (BMR), which is substantially variable indicator among individuals (Johnstone, Murison, Duncan, Rance, \& Speakman, 2005). Higher BMR proposes a higher energy expenditure which would be translated into an increased loss of body and skeletal muscle mass during FD. However, myostatin $\mathrm{KO}$ mice are not showing higher BMR than WT counterparts when BMR is normalized to lean mass or total body mass (Guo et al., 2009; McPherron \& Lee, 2002). This might be associated with unchanged or even decreased size of internal organs in myostatin $\mathrm{KO}$ mice, which also play a significant role in overall BMR (Konarzewski \& Diamond, 1995). Irrespective of BMR, myostatin KO mice seem to have metabolic changes in skeletal muscle. Although there were no differences in the rate of whole body lipid oxidation, but reduced lipid oxidation in skeletal muscle and increased glucose utilization was observed in myostatin $\mathrm{KO}$ mice (Guo et al., 2009). This is in agreement with findings that skeletal muscle of myostatin deficient mice is more glycolytic (i.e. having more fast twitch fibres) than muscle of WT mice (Girgenrath et al., 2005). Thus, the evidence suggests that alteration in the metabolism rather than increased metabolic rate might be of major importance in greater FDinduced muscle wasting in myostatin-deficient mice compared to WT controls.

We have also studied the effect of mouse strain on FD induced muscle atrophy. Our results show that $\mathrm{BEH}+/+$ mice experience greater $\mathrm{FD}$-induced muscle atrophy than $\mathrm{C} 57 \mathrm{BL} / 6 \mathrm{~J}$ mice. It is well known that muscle proteins are broken down to amino acids which are released into circulation and used for gluconeogenesis and greater levels of fat can reduce mobilization of muscle protein for energy during starvation (Cuendet et al., 1975; Runcie \& Thomson, 1970). C57BL/6J mice are approximately two fold lighter than $\mathrm{BEH}+/+$, but have greater muscle to body mass ratio than $\mathrm{BEH}+/+$. Thus $\mathrm{C} 57 \mathrm{BL} / 6 \mathrm{~J}$ mice have greater relative muscle mass and might have less fat than $\mathrm{BEH}+/+$ mice. Lower fat mass might promote greater utilization of skeletal muscle protein for energy in $\mathrm{C} 57 \mathrm{BL} / 6 \mathrm{~J}$ mice compared to $\mathrm{BEH}+/+$ mice. Differences in between the strains might also be of importance for muscle wasting during FD. Smaller animals have higher mass specific BMR which is related to larger surface area to volume ratio compared to bigger animals (Hochachka, Darveau, Andrews, \& Suarez, 2003). It is, however, unclear if this prediction derived from studies of different mammalian species of markedly different body masses can be transferred into mouse strains.

Specific skeletal muscles showed differences in muscle atrophy after FD. Soleus muscle tended to show smaller atrophy compared to other skeletal muscles in all three mouse strains. This might be at least partially related to fibre type composition. When atrophy is induced by inactivity, unloading or denervation slow twitch muscles are affected more than fast twitch muscles (Roy, Baldwin, \& Edgerton, 1991; Schiaffino et al., 2013). When atrophy is loading independently and associated with increased hormone or cytokine signalling, then it seems that fast twitch muscles and/or fast twitch fibres show greater susceptibility to muscle atrophy (Roy et al., 1991). In agreement with our findings, Li and Goldberg (1976) also found that soleus muscle is less sensitive to starvation compared to the faster contracting muscles and proposed that these differences might be due to lower sensitivity of slow twitch muscles to corticosteroids compared to fast twitch muscles (Goldberg \& Goodman, 1969; Livingstone, Johnson, \& Mastaglia, 1981). Myostatin KO mice have a higher content of fast twitch fibres (Girgenrath et al., 2005). Higher content of fast twitch fibres in skeletal muscles might be a key factor in causing greater atrophy in BEH than $\mathrm{BEH}+/+$ mice after FD. Indeed, soleus showed a significant loss of muscle mass only in BEH mice.

In summary, our results show that BEH mice with myostatin dysfunction have greater muscle mass, but experience more severe muscle atrophy when subjected to FD compared to $\mathrm{BEH}+/+$ mice with functioning myostatin. These findings do not support the hypothesis that myostatin targeting could preserve skeletal muscle mass during food restriction. However, BEH mice show constitutive loss of myostatin function and might not be the most appropriate model to evaluate effects of myostatin inhibition on muscle atrophy. An overt phenotype differences between $\mathrm{BEH}$ and $\mathrm{BEH}+/+$ were established before the experiment with FD. Studies with conditional myostatin $\mathrm{KO}$ or inhibition during the period of FD are needed to test this hypothesis appropriately. We have also found that C57BL/6 J mice show greater FD induced muscle atrophy than $\mathrm{BEH}+/+$ mice. We propose that lower levels of body 
fat and higher metabolic rate could potentially be responsible for this increased rate of muscle atrophy in $\mathrm{C} 57 \mathrm{BL} / 6 \mathrm{~J}$ mice compared to $\mathrm{BEH}+/+$ mice.

\section{CONCLUSIONS}

1. Mice with myostatin dysfunction are more sensitive to muscle atrophy after FD supposedly due to reduced fat mass and increased fast twitch fibre content in skeletal muscle.

2. C57BL/6J mice show greater loss of muscle mass during FD compared to $\mathrm{BEH}+/+$ mice. This could also be due to lower fat mass in C57BL/6 J mice compared to $\mathrm{BEH}+/+$ mice. However, differences in metabolic rate and muscle fibre type composition might also play a role.

\section{REFERENCES}

Allen, D. L., Cleary, A. S., Lindsay, S. F., Loh, A. S., \& Reed, J. M. (2010). Myostatin expression is increased by food deprivation in a muscle-specific manner and contributes to muscle atrophy during prolonged food deprivation in mice. Journal of Applied Physiology, 109(3), 692-701. doi: 10.1152/japplphysiol.00504.2010 Amthor, H., Macharia, R., Navarrete, R., Schuelke, M., Brown, S. C., Otto, A., ... \& Patel. K. (2007). Lack of myostatin results in excessive muscle growth but impaired force generation. Proceedings of the National Academy of Sciences of the United States of America, 104(6), 1835-1840. doi:10.1073/pnas.0604893104

Anderson, R. M., \& Weindruch, R. (2012). The caloric restriction paradigm: Implications for healthy human aging. American Journal of Human Biology, 24(2), 101106. doi: 10.1002/ajhb.22243

Bogdanovich, S., Krag, T. O., Barton, E. R., Morris, L. D., Whittemore, L. A., Ahima, R. S., \& Khurana, T. S. (2002). Functional improvement of dystrophic muscle by myostatin blockade. Nature, 420(6914), 418-421. doi:10.1038/nature01154

Bünger, L., Ott, G., Varga, L., Schlote, W., Rehfeldt, C., Renne, U., ... \& Hill, W. G. (2004). Marker-assisted introgression of the Compact mutant myostatin allele MstnCmpt-dl1Abc into a mouse line with extreme growth effects on body composition and muscularity. Genetics Research, 84(3), 161-173.

Collins-Hooper, H., Sartori, R., Giallourou, N., Matsakas, A., Mitchell, R., Makarenkova, H. P., ... \& Patel, K. (2015). Symmorphosis through dietary regulation: A combinatorial role for proteolysis, autophagy and protein synthesis in normalising muscle metabolism and function of hypertrophic mice after acute starvation. PLoS One, 10(3), e0120524. doi: 10.1371/journal.pone.0120524

Costelli, P., Muscaritoli, M., Bonetto, A., Penna, F., Reffo, P., Bossola, M., ... \& Fanelli, F. (2008). Muscle myostatin signalling is enhanced in experimental cancer cachexia. European Journal of Clinical Investigation, 38(7), 531-538. doi: 10.1111/j.1365-2362.2008.01970.x

Cuendet, G. S., Loten, E. G., Cameron, D. P., Renold,A. E., \& Marliss, E. B. (1975). Hormone-substrate responses to total fasting in lean and obese mice. The American Journal of Physiology, 228(1), 276-283.

Elia, M., \& Stratton, R. J. (2000). How much undernutrition is there in hospitals? British Journal of Nutrition, 84(3), 257-259. doi: http://dx.doi. org/10.1017/S0007114500001525
Gilson, H., Schakman, O., Combaret, L., Lause, P., Grobet, L., Attaix, D., ... \& Thissen, J. P. (2007). Myostatin gene deletion prevents glucocorticoidinduced muscle atrophy. Endocrinology, 148(1), 452460. doi: http://dx.doi.org/10.1210/en.2006-0539

Girgenrath, S., Song, K., \& Whittemore, L. A. (2005). Loss of myostatin expression alters fiber-type distribution and expression of myosin heavy chain isoforms in slowand fast-type skeletal muscle. Muscle \& Nerve, 31(1), 3-40.

Goldberg, A. L., \& Goodman, H. M. (1969). Relationship between cortisone and muscle work in determining muscle size. The Journal of Physiology, 200(3), 667675. doi: 10.1113/jphysiol.1969.sp008715

Gonzalez-Cadavid, N. F., Taylor, W. E., Yarasheski, K., Sinha-Hikim, I., Ma, K., Ezzat, S., ... \& Bhasin, S. (1998). Organization of the human myostatin gene and expression in healthy men and HIV-infected men with muscle wasting. Proceedings of the National Academy of Sciences of the United States of America, 95(25), 14938-14943.

Gruson, D., Ahn, S. A., Ketelslegers, J. M., \& Rousseau, M. F. (2011). Increased plasma myostatin in heart failure. European Journal of Heart Failure, 13(7), 734-736. doi: 10.1093/eurjhf/hfr024

Guo, T., Jou, W., Chanturiya, T., Portas, J., Gavrilova, O., \& McPherron, A. C. (2009). Myostatin inhibition in muscle, but not adipose tissue, decreases fat mass and improves insulin sensitivity. PLoS One, 4(3), e4937. doi: 10.1371/journal.pone.0004937

Hochachka, P. W., Darveau, C. A., Andrews, R. D., \& Suarez, R. K. (2003). Allometric cascade: A model for resolving body mass effects on metabolism. Comparative Biochemistry and Physiology Part A: Molecular \& Integrative Physiology, 134(4), 675-691. doi: 10.1016/ S1095-6433(02)00364-1

Ji, S., Losinski, R. L., Cornelius, S. G., Frank, G. R., Willis, G. M., Gerrard, D. E., ... \& Spurlock, M. E. (1998). Myostatin expression in porcine tissues: Tissue specificity and developmental and postnatal regulation. The American Journal of Physiology, 275(4), 12651273.

Johnstone, A. M., Murison, S. D., Duncan, J. S., Rance, K. A., \& Speakman, J. R. (2005). Factors influencing variation in basal metabolic rate include fat-free mass, fat mass, age, and circulating thyroxine but not sex, circulating leptin, or triiodothyronine. The American Journal of Clinical Nutrition, 82(5), 941-948. 
Konarzewski, M., \& Diamond, J. (1995). Evolution of basal metabolic rate and organ masses in laboratory mice. Evolution, 49, 1239-1248.

Lee, S. J. (2004). Regulation of muscle mass by myostatin. Annual Reviews of Cell and Developmental Biology, 20, 61-86. doi: 10.1146/annurev.cellbio.20.012103.135836

Li, J. B., \& Goldberg, A. L. (1976). Effects of food deprivation on protein synthesis and degradation in rat skeletal muscles. American Journal of Physiology, 231(2), 441-448.

Lin, J., Arnold, H. B., Della-Fera, M. A., Azain, M. J., Hartzell, D. L., \& Baile, C. A. (2002). Myostatin knockout in mice increases myogenesis and decreases adipogenesis. Biochemical and Biophysical Research Communications, 291(3), 701-706. doi:10.1006/bbrc.2002.6500

Lionikas, A., Kilikevicius, A., Bünger, L., Meharg, C., Carroll, A. M., Ratkevicius, A., ... \& Blizard, D. A. (2013b). Genetic and genomic analyses of musculoskeletal differences between BEH and BEL strains. Physiological Genomics, 45(20), 940-947. doi: 10.1152/physiolgenomics.00109.2013

Lionikas, A., Smith, C. J., Smith, T. L., Bünger, L., Banks, R. W., \& Bewick, G. S. (2013a). Analyses of muscle spindles in the soleus of six inbred mouse strains. Journal of Anatomy, 223(3), 289-296. doi: 10.1111/joa.12076

Lipina, C., Kendall, H., McPherron, A. C., Taylor, P. M., \& Hundal, H. S. (2010). Mechanisms involved in the enhancement of mammalian target of rapamycin signalling and hypertrophy in skeletal muscle of myostatin-deficient mice. FEBS Letters, 584(11), 24032408. doi: 10.1016/j.febslet.2010.04.039

Livingstone, I., Johnson, M. A., \& Mastaglia, F. L. (1981). Effects of dexamethasone on fibre subtypes in rat muscle. Neuropathology and Applied Neurobiology, 7(5), 381-398. doi: 10.1111/j.1365-2990.1981.tb00240.x Matsakas, A., Romanello, V., Sartori, R., Masiero, E., Macharia, R., Otto, A., ... \& Patel, K. (2013). Food restriction reverses the hyper-muscular phenotype and force generation capacity deficit of the myostatin null mouse. International Journal of Sports Medicine, 34(3), 223-231. doi: 10.1055/s-0032-1312605

McCroskery, S., Thomas, M., Maxwell, L., Sharma, M., \& Kambadur, R. (2003). Myostatin negatively regulates satellite cell activation and self-renewal. The Journal of Cell Biology, 162(6), 1135-1147. doi: 10.1083/ jcb.200207056

McMahon, C. D., Popovic, L., Oldham, J. M., Jeanplong, F., Smith, H. K., Kambadur, R., ... \& Bass, J. J. (2003). Myostatin-deficient mice lose more skeletal muscle mass than wild-type controls during hindlimb suspension. American Journal of PhysiologyEndocrinology and Metabolism, 285(1), 82-87. doi: 10.1152/ajpendo.00275.2002

McPherron, A. C., Lawler, A. M., \& Lee, S. J. (1997). Regulation of skeletal muscle mass in mice by a new TGF-beta superfamily member. Nature, 387(6628), 8390. doi:10.1038/387083a0
McPherron, A. C., \& Lee, S. J. (2002). Suppression of body fat accumulation in myostatin-deficient mice. The Journal of Clinical Investigation, 109(5), 595-601. doi: 10.1172/JCI13562

Personius, K. E., Jayaram, A., Krull, D., Brown, R., Xu, T., Han, B., ... \& Welle, S. (2010). Grip force, EDL contractile properties, and voluntary wheel running after postdevelopmental myostatin depletion in mice. Journal of Applied Physiology, 109(3), 886-894. doi: 10.1152/ japplphysiol.00300.2010

Plant, P. J., Brooks, D., Faughnan, M., Bayley, T., Bain, J., Singer, L., ... \& Batt, J. (2010). Cellular markers of muscle atrophy in chronic obstructive pulmonary disease. American Journal of Respiratory Cell and Molecular Biology, 42(4), 461-471. doi: 10.1165/rcmb.2008-0382OC

Roy, R. R., Baldwin, K. M., \& Edgerton, V. R. (1991). The plasticity of skeletal muscle: Effects of neuromuscular activity. Exercise and Sports Sciences Reviews, 19, 269-312.

Runcie, J., \& Thomson, T. J. (1970). Prolonged starvation - a dangerous procedure? British Medical Journal, 3(5720), 432-435.

Schiaffino, S., Dyar, K. A., Ciciliot, S., Blaauw, B., \& Sandri, M. (2013). Mechanisms regulating skeletal muscle growth and atrophy. The FEBS Journal, 280(17), 4294-4314. doi: 10.1111/febs. 12253

Schuelke, M., Wagner, K. R., Stolz, L. E., Hübner, C., Riebel, T., Kömen, W., ... \& Lee, S. J. (2004). Myostatin mutation associated with gross muscle hypertrophy in a child. The New England Journal of Medicine, 350(26), 2682-2688. doi: 10.1056/NEJMoa040933

Varga, L., Szabó, G., Darvasi, A., Müller, G., Sass, M., \& Soller, M. (1997). Inheritance and mapping of Compact (Cmpt), a new mutation causing hypermuscularity in mice. Genetics, 147(2), 755-764.

Wagner, K. R., McPherron, A. C., Winik, N., \& Lee, S. J. (2002). Loss of myostatin attenuates severity of muscular dystrophy in mdx mice. Annals of Neurology, 52(6), 832-836.

Welle, S., Bhatt, K., \& Pinkert, C. A. (2006). Myofibrillar protein synthesis in myosta- tin-deficient mice. American Journal of Physiology - Endocrinology and Metabolism, 290(3), 409-415. doi: 10.1152/ajpendo.00433.2005

Whittemore, L. A., Song, K., Li, X., Aghajanian, J., Davies, M., Girgenrath, S., ... \& Wolfman, N. M. (2003). Inhibition of myostatin in adult mice increases skeletal muscle mass and strength. Biochemical and Biophysical Research Communications, 300(4), 965971. doi:10.1016/S0006-291X(02)02953-4

Wolfe, R. R. (2006). The underappreciated role of muscle in health and disease. The American Journal of Clinical Nutrition, 84(3), 475-482.

Yanai, H. (2015). Nutrition for Sarcopenia. Journal of Clinical Medicine Research, 7(12), 926-931. doi: $10.14740 /$ jocmr $2361 \mathrm{w}$ 